Middle East Journal of Science(MEJS)

journal homepage: http://mejs.ineseg.org/

CONTRIBUTIONS TO BINGOL FLORA AND BEEPKEEPING

\title{
Ömer Kiliç ${ }^{1}$ Mehmet Ali Kutlu',
}

${ }^{1}$ Technical Science Vocational College, Bingol University, 12100, Bingöl, Türkiye

${ }^{* 2}$ Beekeeping, Research, Development, Applications Centre Offices, Bingol University,Turkey

*omerkilic77@gmail.com

Turkey has rich plant biodiversity because of different ecological conditions and important position. Research until today shows that plant diversity of our country is more than Europe. Also limited floristic research and discovered new species recent years in Bingöl prove that plant diversity of Bingöl is reach. Floristic studies which were carried out in Bingöl mostly shows that Asteraceae, Fabaceae and Lamiaceae families includes most plant taxa. Also researches conducted in Bingol have shown that the plants visited most often by bees are of the families Lamiaceae, Asteraceae and Fabaceae. These studies and new species discovered in Bingol recently, constitute scientific evidence that the Bingol vegetation is rich, especially for the plants the bees use to collect most of the nectar. As a result, this study has contributed to a certain extent to Bingöl Flora and beepkeeping. Furthermore, with this research basic datas have obtained to contribute and set light to Bingöl and region flora and beepkeeping. Additionally, necessary precautions to prevent damage to the plants and sensitivity are essential in order to improve the beekeeping in Bingol, to provide benefits to rural development and to increase the diversity and distribution of the natural vegetation.

Key words: Bingöl, beepkeping, bee, flora 


\section{BİNGÖL FLORA VE ARICILIĞI'NA KATKILAR}

Türkiye ekolojik şartların farklılığından ve önemli konumundan dolayı bitki biyoçeşitliliği bakımından zengin ülkelerden biridir. Bu güne kadar yapılmış olan araştırmalar gösteriyor ki ülkemizin bitki çeşitliliği Avrupa'dan fazladır. Yine Bingöl'de yapılmış olan sınırl floristik çalışmalar ve son yıllarda keşfedilen yeni bitki türleri, Bingöl'ün bitki çeşitliliği açısından zenginliğini ispatlamaktadır. Bingöl'de yapılmış floristik çalışmaların çoğunda en fazla bitki taksonu içeren familyalar Asteraceae, Fabaceae ve Lamiaceae olarak tespit edilmiştir. Yine Bingöl'de yapılmış arıcılık ile ilgili çalışmalarda arlartn en fazla ziyaret ettikleri bitkiler genelde Lamiaceae, Asteraceae ve Fabaceae familyalarında toplanmıştır. Bingöl'de son yllarda floristik çalışma sonucu elde edilen veriler ile keşfedilen yeni bitki türleri Bingöl florasinin ve arıların en fazla nektar topladiklar bitkiler bakımından Bingöl'ün zengin olduğunun bilimsel kanıtlarıdır. Sonuç olarak yapılmış olan bu çalışma ile Bingöl ili flora ve arıcılı̆̆ına belirli ölçüde katkı sağlanmıştır. Ayrıca bu çalışma ile, Bingöl ve bölgemizde bundan sonra yapılacak olan floristik ve arıcılıkla ilgili çalışmalara ışık tutacak ve kaynak olacak temel veriler elde edilmiştir. Tüm bunlara ek olarak, Bingöl'de ki arıcılı̆̆ ilk sıralara taşımak, kırsal kalkınmasına fayda sağlamak, doğal bitki örtüsünün çeşitlilik ve yayılışını artırmak için gerekli önlemlerin alınması ve hassasiyetin gösterilmesi gerekmektedir.

Anahtar Kelimeler: Bingöl, arıcılık, arı, flora.

\section{Giriş}

Coğrafi konumu, jeomorfolojik yapısı, çok çeşitli toprak tipleri ve iklim çeşitliliğine sahip oluşu nedeniyle farklı ve zengin bir floraya sahip olan ülkemiz, bitki çeşitliliği ve zenginliği açısından dünya ülkelerinin başında gelir. Türkiye'nin bitki örtüsü flora kompozisyonu yönünden ele alındığında, üç fitocoğrafik bölgenin geçiş sahası üzerinde bulunmakta olup, ülkemizin kuzeyinde Avrupa-Sibirya; doğu, orta ve güneydoğu Anadolu'da İran-Turan; güney ve batısında Akdeniz flora bölgeleri yer almaktadır[1]. Tüm Avrupa Kıtası'nda yaklaşı 12.000 bitki türü yer alırken ülkemizde güncel rakamlarla 13.000'den fazla bitki taksonu bulunmakta ve yeni bitki türlerinin keşfedilmesiyle bu say1 her geçen yıl artmaktadır. Ülkemizin bu derece zengin bitki türü ve çeşitliliğine sahip olmasının bazı önemli sebeplerini şöyle sıralayabiliriz; çok çeşitli habitat tiplerini içermesi ve üç fitocoğrafik bölgenin (İran-Turan, Avrupa-Sibirya ve Akdeniz) kesiştiği yerde olması, birçok cinsin gen merkezi ve anavatanı konumunda bulunması, Asya ile Avrupa kıtalarını birbirine bağlayan konumda olması, ekolojik farklılıklara sahip olması, zengin su kaynaklarına sahip olması, 0-5000 metreler arasında değişen yükseklik farklılıklarına sahip olması, buzul çağında Türkiye'de ki bitki örtüsünün diğer ülkelerden daha 
az zarar görmesi, Anadolu'nun doğusu ve batısı arasında ekolojik farklılıklar bulunması ve bu ekolojik farklılıkların bitki türü ve çeşitliliğine yansıması[2]. Bozkır (Step), sulak alan, kayalık, ormanlık alanlar gibi farklı yaşam alanlarına sahip olması, farklı ekolojik özelliklere sahip olması ve son yıllarda yapılmış olan floristik çalışmalar ve birkaç yıl içinde keşfedilen yeni bitki türleri de Bingöl'ün bitki sayısı ve çeşitliliği açısından zenginliğini göstermektedir[2-5]. Ancak dünya ve ülkemiz florası, plansız kentleşme, ormanlardaki usulsüz kesimler, orman yangınları, sanayi ve evsel atıklarla çevrenin kirletilmesi, radyasyon yayılımı, tarım ilaçlarının bilinçsiz kullanılması, aşırı otlatma ve erozyon gibi birçok olumsuz nedenlerle sürekli tahrip edilmektedir. Dolayısıyla tüm bu olumsuzluklara karşı, dünya ve özellikle de ülkemizin bitki çeşitlilik ve zenginliğinin korunması için ciddi önlemler alınması gereklidir.

Arıcılığın en önemli amaçlarından biri arı kolonilerinin bulunduğu alandaki ana nektar akımı döneminde var olan bitkisel kaynaklardan arıların nektar, polen ve propolis toplayarak bunları en iyi şekilde arı sütü, arı zehiri, bal ve bal mumu gibi farklı arı ürünlerine dönüştürülmesini sağlamaktır. Bu amaca ulaşmak için arıcılık yapılan yöredeki bitki örtüsünün ve özellikle de arıların nektar almak için en fazla ziyaret ettiği bitkilerin çok iyi tanınması, çiçeklenme ve nektar akımının başlama zamanı ve süresinin iyi bilinmesi gerekir. Çünkü arıcılıktan yüksek verim ve kalite elde edebilmek, koloni verimliliği, koloni gücü ve çalışkanlığının yanı sıra, nektar ve polen kaynakları olan bitki çeşidine ve zenginliğine de bağlıdır[6]. Ülkemizin ve Bingöl'ün zengin bitki örtüsüne sahip olması direk arıcılık faaliyetlerinin de daha elverişli ortamlarda yapılmasını sağlamaktadır. Arıcılık faaliyetleri, yatırımın çok kısa sürede gelire dönüşmesi, diğer sektörlere göre daha az iş gücüne ihtiyaç duyulması, arı ürünlerine iç ve dış pazarlarda talebin fazla olmasından dolayı kârlı bir tarımsal faaliyet haline gelmiştir. Ancak arıcılıkta çalışılan materyal özellikle arı ve bitkiler olduğundan, bu alanda başarılı olmanın yolu öncelikle materyallerin iyi tanınması, arıların en fazla nektar aldıkları bitkiler konusunda bilgi birikiminin olması, gerekli bakım, yöntem ve yönetiminin iyi bilinmesi gerekmektedir. Özellikle ülkemizin doğu kesimleri, tarımsal faaliyetler bakımından baskın olan özelliklerini hala barındırmakta ve kırsal kesimlerde nüfus yoğunluğu görülmektedir. Dolayısıyla arıcılık faaliyetleri, arılık alanlarının belirlenmesi ve alanın floristik yapısı ile arıların en fazla ziyaret ettiği bitkilerin tespit edilmesi bu kesimlerde daha da önem arz etmektedir. Çünkü toprağa bağımlı olmayan, başlangıç için fazla sermayeye ihtiyaç duyulmadan toplumun her bireyi tarafından yapılabilme özelliğinde olan ve birinci yılında gelir getirmeye başlayan arıcılık sektörü kırsal kesimdeki halkımız için kolay bir iş ve kazanç kaynăğdır.

Hazırlanan bu çalışma ile Bingöl'de öne çıkan sektörler arasında olan arıcılık sektörünün özetle ne düzeyde olduğu gösterilerek, ekolojik ve ekonomik değerinin ortaya çıkarılması amaçlanmakta, verilen öneri ve tedbirlerle de bu potansiyelin geliştirilmesi adına atılması gereken adımlar ortaya konmakta ve arıcılık faaliyetlerinin temeli olan bitkiler ile bitki sayısı ve çeşidi bakımından önemli potansiyeli olan Bingöl'de arıcılık faaliyetlerinin sürdürülmesi, geliştirilmesi ve ülke sıralamasındaki yerinin ilk sıralara taşınmasının zaruri olduğuna dikkat çekilmektedir. Ayrıca ilgili kurumların işbirliği içinde, arıcılık faaliyetlerinin daha bilinçli ve verimli sürdürülmesinin, bu çalışmaların daha fazla teşvik edilerek ve özellikle uzmanlardan da destek alınarak ilerletilmesinin ne kadar yerinde ve doğru bir karar olacağı belirtilmeye çalışılmaktadır.. 


\section{Yöntem}

Bingöl ilindeki arıcılık ve floristik faaliyetleri konu alan bu araştırmada materyal olarak Bingöl Tarım İl Müdürlüğü ve Bingöl Arıcılar Birliği'nden alınan sözel ve istatistiki[7] veriler yanında son yıllarda Bingöl ve çevresinde yapılmış olan bilimsel çalışmalar ile arazide yapılan gözlem ve arıcılardan elde edilen bilgiler materyal olarak kullanılmış, yerel kaynaklardan da faydalanılarak Bingöl'de arıcılığı etkileyen doğal ve beşeri faktörler incelenmiş, dünya ve Türkiye ölçeğinde Bingöl'ün arıcılıktaki konumuna dikkat çekilerek elde edilen sonuçlara göre Bingöl'de zengin bir arıcılık ve bitki örtüsü potansiyelinin varlığı yanında bunları olumsuz yönde etkileyen faktörler üzerinde de durularak çözüm önerileri sıralanmıştır. Ayrıca çalışmada Bingöl Üniversitesi araştırıcılarının yaptıkları ve Bingöl çevresinde yapılmış olan flora ve arıcılıkla ilgili bilimsel çalışmalar temel veri kaynakları olarak kullanılmıştır. Bu kapsamda arıcılık faaliyetleri ile canlı ve özellikle de bizlerin hayat ve sağlı̆̆ımız için zaruri ihtiyaç olan bitkileri ve bu zenginlikteki bitki örtümüzü korumak ve bu kapsamdaki çalışmaları sürdürmenin, ülkemiz ve ilimiz ekonomisi açısından getirisinin az olmadığı vurgulanmaktadır.

\section{Bulgular}

Giriş kısmında da özetle belirtildiği gibi yapılmış olan bilimsel çalışmalar Bingöl’ün bitki örtüsü zenginliğini ispatlamaktadır. Yoğun arıcılık faaliyetleri yanında, doğal güzellikleri, çeşitli doğa turizmi (Yayla-Flora-Kış-Akarsu-Av-Mağara Turizm alanlarının olması, Yaban hayatı gözlemciliği ve Doğa Yürüyüşü) etkinliklerinin olması da Bingöl'ün ülkemizde ayrı bir yeri olduğunun göstergeleridir. Bingöl florası ve arıcılığıyla ilgili literatürde az çalışma olup, üniversitemiz araştırıcıları tarafından son yıllarda yapılan bazı flora ve arıcılık çalışmaları ile Bingöl için tespit edilen yeni bitki türleri[8] Bingöl'ün bitki türü sayısı, çeşitliliği ve zenginliğinin ilk göstergeleri olup, ilimizde bu tür floristik ve arıcılıkla ilgili çalışmalar devam ettikçe, Bingöl'ün bitki örtüsü bakımından zenginliği daha da belirginleşecek ve bu durum dolaylı olarak arıcılık faaliyetlerini de olumlu yönde etkileyecektir.
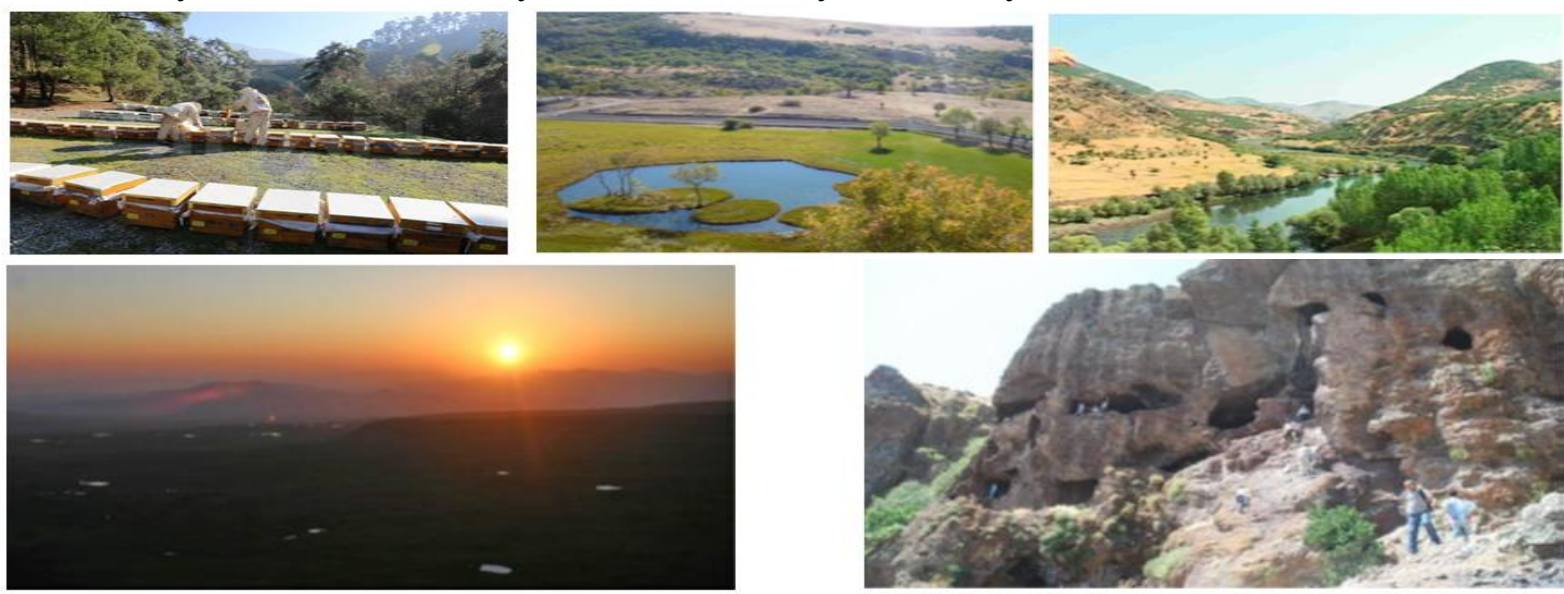

\section{Resim 1. Bingöl'ün Doğal Güzellikleri ve Arıcılık Faaliyetinden Bir Görünüm}

Dikme (Kür) yaylası (Bingöl-merkez) ve Çevresinin Florası isimli çalışma [9]sonucunda, alandan 694 bitki türü saptandı ve bu çalışmada, Bingöl'de arıların en fazla ziyaret ettiği bitki familyaları olan Papatyagiller, Ballıbabagiller ve Baklagiller [10] en fazla bitki türü içeren familyalar olarak tespit edildi. Yine arıların en fazla ziyaret ettiği bitki cinsleri olan Geven (Astragalus), Adaçayı (Salvia), Fiğ (Vicia), Üçgül (Trifolium) ve Papatya (Anthemis)[11] bu çalışmamızda bitki sayısı bakımından en zengin cinsler 
olarak bulundu. Yine Bingöl'de yapılmış, floristik bir çalışmada 353 tür, 123 alttür ve 59 varyete olmak üzere toplam 535 takson tespit edilmiş ve endemik ile nadir toplam 29 bitkinin tehlike kategorileri tespit edilerek, bu özel ve nadir bitkilerin korunmaları hususunda önerilerde bulunulmuş ve bu çalışmada da Bingöl yöresinde arıların en çok nektar topladığı Papatyagiller, Ballıbabagiller ve Baklagiller[12] familyaları ile geven, üçgül ve fiğ en fazla bitki türü içeren cinsler arasında tespit edilmiştir [13]. Bingöl'de yapılmış olan bu floristik çalışmalarla Bingöl'ün doğal bitki örtüsü ve özellikle de arıların en fazla nektar topladığı bitkiler açısından zengin olduğu ispatlanmış ve bu çalışmalar devam ettikçe bu zenginliğin ve arıcılık faaliyetleri açısından öneminin daha da farkına varılacaktır.

Arılı kovanların konulduğu ve arıcının çalıştığ yere "arılık" denilip, arılık seçiminde rüzgar, nem, sıcaklık, gölge, arazi yapısı, temiz su kaynağı, yerleşim yerine uzaklık, zirai mücadele alanları ve en önemlisi de alanın bitki örtüsü gibi faktörler rol oynar. Bir bölgede arıların istifade edebileceği yeteri kadar çiçek yoksa arıcının bütün gayretleri boşa gidebilir ve yapılan arıcılık da ekonomik olmaz. Çiçekler bala yalnız rengini değil kokusunu da verir, bu sebeple balın bolluğu ve kalitesi büyük ölçüde bölgede bulunan çiçeklere bağlıdır. Dolayısıyla kovanların bulunduğu çevrede ne kadar çok ve farklı çiçekli bitki türü varsa alandan elde edilen balın verimi ve kalitesi de o derece artacaktır. Bingöl ve çevre illerde yapılan arıcılık faaliyetleriyle ilgili çalışmalarda belirtildiği gibi, arıların polen almak için en fazla ziyaret ettikleri bitkiler genelde Ballıbabagiller (Lamiaceae), Papatyagiller (Asteraceae) ve Baklagiller (Fabaceae) familyalarında toplanmıştır[14]. Arıcılık faaliyetlerinde bulunanlar, kovanlarını özellikle bu familya üyelerinin zengin olduğu bölgelere yerleştirmeyi tercih ederler ki; buralardan elde edilen ballarda kalite ve verimin arttı̆̆ da gözlemlenmiştir. Bingöl'de yapılan floristik çalışmalarda bu familya ve cins üyelerinin bitki sayısı bakımından ilk sıralarda yer alması [15] arıcılık faaliyetleri açısından manidardır. Ayrıca bu tür floristik çalışmalar, arıcıların arılık yerlerini belirlemelerinde ve balın verim ile kalitesinin artmasında önemli yol göstericilerdir. Arıların en fazla ziyaret ettiği bitkilerin bulunduğu Ballıbabagiller (Lamiaceae) familyası çoğunlukla güzel kokulu, bir ya da çok yıllık, otsular ve nadiren çalıları kapsayan çiçekli bir bitki familyasıdır. Familya üyelerinin çoğu tıbbi, aromatik, kokulu bitkileri içerip, bu bitkiler bol miktarda uçucu ve aromatik yağ içerdiklerinden ilaç hammaddesi olarak, kozmetik sanayinde, çay olarak tüketilmekte, güzel kokulu ve güzel görünümlü çiçeklerinden dolayı süs bitkisi olarak kullanılması gibi birçok değerlendirme alanı vardır. Ayrıca, bu familyadaki bitkiler bol nektarlı olduklarından, arılar bal üretmek amacıyla öncelikli ve daha çok bu bitkileri ziyaret edip balözü toplarlar; bu durum arıcılık sektörü açısından Ballıbabagiller familyasındaki bitkilerin önemini göstermektedir. İnsan sağlığı ve yaşamı açısından önemli ve çok farklı kullanım alanlarının olduğu Ballıbabagiller familyasının ülkemizde 46 cinsi, 700'ün üzerinde türü bulunmakta ve bunların yaklaşık \%45'i ülkemiz için endemiktir (ülkemize özgü). Adaçayı (Salvia), Kekik (Thymus), Nane (Mentha), Kedinanesi (Nepeta), Fesleğen (Ocimum), Kayakekiği (Satureja), Ballıbaba (Lamium), Mercanköşk (Origanum), Dağçayı (Sideritis), Lavanta (Lavandula), Oğulotu (Melissa), Zahter (Thymbra) ve Biberiye (Rosmarinus), ballıbabagiller familyasının en önemli, bilinen ve sık duyulan cinsleri arasındadır.

Baklagiller familyasındaki en önemli, değerli ve ülkemizde 400'ün üzerinde türü olan Geven (Astragalus) türleri de nektar alabilmek için arıların sıklıkla ziyaret ettiği bitkiler arasındadır. Bingöl'de arıcıların yoğun olarak konakladıkları merkeze bağlı Kür yaylası ve çevresinde yapılan floristik çalışmada [15] alandan 19 adet geven bitkisi ve 63 adet Ballıbabagiller familyasına ait bitki tespit 
edilmiştir. Yine Bingöl'de yapılmış olan floristik bir çalışma sonucunda çalışma alanından 31 adet Ballıbabagiller (Lamiaceae) üyesi ve 12 adet geven taksonu tespit edilmiştir (Sinan \& Behçet, 2014). Bu tür bilimsel çalışmalar Bingöl bitki örtüsünün, özellikle de arıların en fazla nektar topladıkları bitkiler bakımından zengin olduğunun bilimsel kanıtlarıdır.

\section{Sonuçlar}

Bu sonuçlar ve Bingöl'ün ekolojik farklılıkları ile bitki örtüsündeki çeşitlilik ve zenginliği, arıcılık faaliyetlerinin ideal olarak yapıldığının ve neden balıyla meşhur olduğunun göstergeleridir. Ancak ne yazık ki Bingöl'ün arıcılık faaliyetleri konusunda, ülkemizdeki sıralaması ilk yedi il arasında bile değildir. İşte Bingöl'de ki arıcılığı ilk sıralara taşımak, ilimizin kırsal kalkınmasına fayda sağlamak ve doğal bitki örtüsünün çeşitlilik ve yayılışını artırmak için, Bingöl'de ki arıc1lık faaliyetleri konusunda ilgililerin desteklerini ve kurumlar arası işbirliğinin sürdürülmesi ve bu kapsamdaki çalışmaların artarak devam etmesi gerekmektedir. Anıcılığın temel amacı arı kolonilerinin bulunduğu yöredeki bitkisel kaynaklardan nektar, polen, propolis toplayarak bunları farklı arı ürünlerine dönüştürülmesini sağlamaktır. Bu amaca ulaşabilmek için arıcıların, arılık alanındaki florayı, çiçeklenme ve nektar akımının başlama ve devam süresini iyi bilmesi gerekir. Ayrıca bu tür çalışmaların devamı açısından doğal bitki örtüsünü ve özellikle de arıların en çok ziyaret ettiği Ballıbabagiller familya üyelerinin daha iyi tanınması, zarar görmemesi için gerekli önlemlerin alınması ve hassasiyetin gösterilmesi gerekmektedir. Bu önlemlerin bazılarını şöyle sıralayabiliriz: doğadan bitki toplamanın azalması için, labaratuvar koşullarında mikroüretimle bitki üretiminin artırılması ve bu üretim yöntemini artırmak için teşvik ve desteklerin devam etmesi. Tarım Bakanlığımızın son yıllarda uygulamaya başladığı ve şu an Bingöl'de ve birçok ilimizde uygulanmaya başlanan ıtrî ve tıbbi bitkiler ile boya bitkileri üretiminin geliştirilmesi projesi kapsamındaki çalışmalar arttıkça ülkemiz ekonomisine ciddi katkı sağlanacak, bitkisel kaynaklı çalışmalarda dışa bağımlılı̆̆ımız azalacak, doğadan toplanma azalacak böylece doğal bitki örtüsü ve özellikle tıbbi, aromatik bitkilerin en fazla bulunduğu ve arıların en çok ziyaret ettiği Ballıbabagiller familyasındaki bitkiler doğada daha fazla varlığını ve yayılışını sürdürme imkanı bulacak, bu ve benzeri projelerin sürdürülmesinin ne kadar anlamlı olduğu daha iyi anlaşılacaktır. Bitki biyokaçakçılığıyla ilgili yasal tedbirlerin artırılması ve uygulanmaya devam edilmesi. Ülkemizde florada mevcut olan ancak kültür alanlarında üretimi konusunda henüz çalışmaların olmadığı bitkilerin kültür alanlarında yetiştirilmesi konusundaki çalışmaların artırılması. En önemlisi de bizlerin doğal bitki örtüsünü ve özellikle de arıların en fazla ziyaret ettiği bitki üyelerinin doğal alanlarında korunması ve tanınması için farkındalığın oluşturulması ve hassasiyet bilincinin artırılması gerekmektedir. Ayrıca, ilgili kurumların işbirliklerini artırarak, konunun uzmanlarından faydalanarak, çalıştay, konferans ve bilimsel çalışma gibi etkinliklere devam ederek; hepimizin milli, vicdani ve insani olan bu sorumluluğumuza daha da dikkat çekerek gerekli hassasiyeti gösterebiliriz. 


\section{Kaynakça}

[1] Akman, Y. (1993). Biyocoğrafya, Palme yayınları, 379 s, Ankara.

[2] Kilic, O., \& Bagcı, E. (2011). Aşağıçakmak Köyü ile Keban Baraj Gölü (Elazığ) Arasındaki Sahanın Florası. Ot Sistematik Botanik Dergisi, 18, 79-130.

[3] Sinan A., \& Behçet L. (2014). The flora of Altıkardeş Mountain and its surroundings (Genç, Bingöl / Turkey) Bio. Dicon, 7/3, 98-116.

[4] Kilic, O., \& Yıldırımlı, Ş. (2014a). Bingöl Merkez Dikme yaylası ve çevresinin fulorası. Ot Sistematik Botanik Dergisi. 21, 69-126.

[5] Yıldırımlı, Ş., \& Kilic, O. (2014). Sivas ve Bingöl illerinden üç yeni tür. Ot Sistematik Botanik Dergisi. 21, 1-14.

[6] Kilic, O., \& Yıldırıml1, Ş. (2014b). New native and cultivated floristic records for the square in the flora of Turkey. Ot Sistematik Botanik Dergisi. 21, 47-68.

[7] Bijev, B. (1958). Rikovodstvo Za Uprajneniya Po Pçelarstvo. 27-34, Sofya, Bulgaria.

[8] Bakoğlu, A., Kutlu, M.A., \& Bengü, A.Ş. (2014). Bingöl İlinde Arıların Yoğun Olarak Konakladıkları Alanlarda Üretilen Ballarda Bulunan Polenlerin Tespiti. Türk Tarım ve Doğa Bilimleri Dergisi. 1(3), 348-353.

[9] Kilic, O., Kutlu, M.A., \& Ozdemir, F.A. (2016). Pollen analysis of honey from the Hizan district of Bitlis province, eastern region of Turkey. International Journal of Plant, Animal and Environmental Sciences. 6, 324-331.

[10] Kutlu, M.A., Bakoglu, A. \& Batmaz, B. (2005). Fırat Üniversitesi Bingöl Meslek Yüksek Okulu Arıcılık Programınca yetiştirilen farklı yaşlardaki ana arıların (Apis mellifera L. ) koloni performansları. Doğu Anadolu Bölgesi Araştırmaları Cilt 4 say 1.

[11] Bakoğlu, A., Kutlu, M.A. \& Bengü A.Ş. (2014). Bingöl İlinde Arıların Yoğun Olarak Konakladıkları Alanlarda Üretilen Ballarda Bulunan Polenlerin Tespiti. Türk Tarım ve Doğa Bilimleri Dergisi. 1(3), 348-353.

[12] Sandal, E.Kaya., \& Kan, Celal. (2013). Bingöl İli’nde Arıcılık Faaliyetleri. Türk Coğrafya Dergisi. 60, 1-12.

[13] www.aricilik.gov.tr/egitim_yayin/istatistik

[14] www.ibb.gov.tr/kurumsal/ArilikYerininSecimi.

[15] Pirim, L., Çan M.F., Sönmez M.M. (2011). Bingöl arıcılık raporu. 